\title{
MOTHER-INEANT SEPARATION IN SQUIRREL MONKEYS LIVING IN A GROUP
}

$$
\text { by }
$$

Byron Clarence Jones

\begin{abstract}
A Thesis Submitted to the Faculty of the DEPARTMENT OF PSYCHOLOGY
\end{abstract}

In Partial Fulfillment of the Requirements For the Degree of MASTER OF ARTS In the Graduate college THE UNIVERSITY OF ARIZONA 
STATEMENT BY AUTHOR

This thesis has been submitted in partial fulfillmint of requirements for an advanced degree at The University of Arizona and is deposited in the University Library to be made available to borrowers under rules of the Library.

Brief quotations from this thesis are allowable without special permission, provided that accurate acknowledgment of source is made. Requests for permission for extended quotation from or reproduction of this manuscript in whole or in part may be granted by the head of the major department or the Dean of the Graduate college when in $h$ is judgment the proposed use of the material is in the interest of scholarship. In all other instances, however, permission must be obtained from the author.

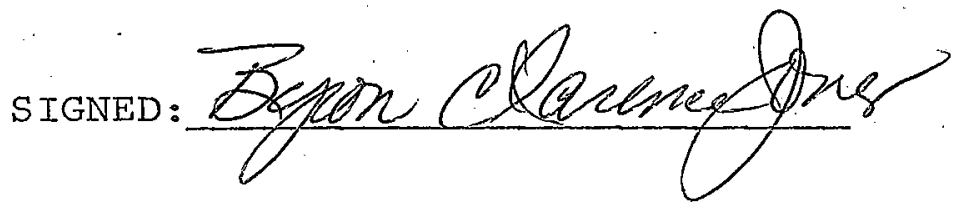

APPROVAL BY THESIS DIRECTOR

This thesis has been approved on the date shown below:

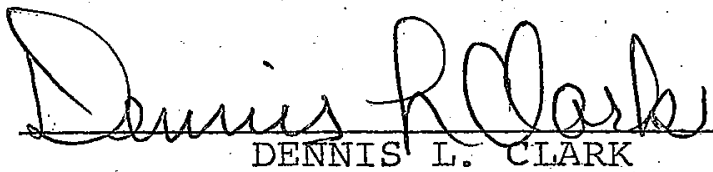

Assistant Professor of Psychology

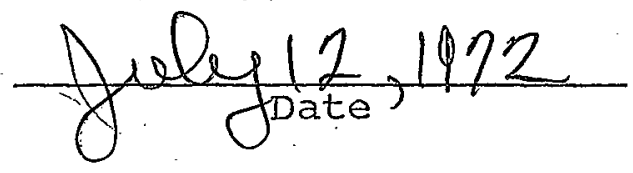




\section{ACKNOWLEDGMENTS}

The author expresses his sincere appreciation to Dr. Dennis L. Clark for his guidance in the designing, writing and data analysis of this study, and to Drs. James E. King and Glenn $M$. White for their constructive criticism of this manuscript. 
TABLE OF CONTENTS

Page

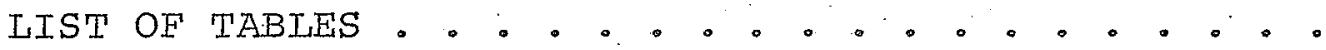

V

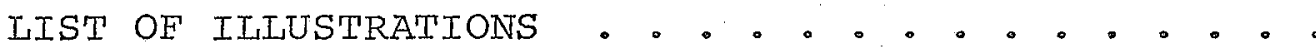

$\vee i$

ABSTRACT

INTRODUCTION

1

METHOD

Subjects - . . . . . . . . . . . . . .

Apparatus. .0 .0 .0 .0 .0 .0 .0 .0 .00$

Procedure . . . . . . . $.0 .0 . .0 .0 .0$

Care and Maintenance of the Subjects .

Experimental Treatment . . . . . . .

Statistical Analysis of Results . . . . .

vii

4

4

RESULTS

10

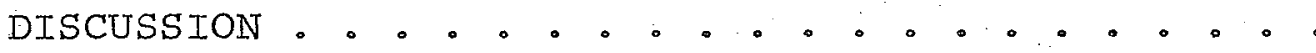

APPENDIX A: TABLES OF MEAN DURATIONS FOR COMBINED

DAYS AND SELECTED DAYS $\circ . . \cdots .$.

21

APPENDIX B: ANALYSIS OF VARIANCE SUMMARY TABLES

FOR THE BEHAVIORS SCORED

REFERENCES 
LIST OE TABLES

Table

Page

A-1 Mean Duration (in Seconas) per Observation Session of Scored Behaviors . ......

A-2 Mean Duration of Crying in seconds for Each subject for Selected Days of the Experiment . . . . . . . . . . . .

A-3 Mean Duration of Selected Behaviors on the Last Day of Preseparation, Separation and Reunion .........

B-1 Analysis of Variance Summary Table for Mean Duration of Activity Play .....

B-2 Analysis of Variance summary Table for Mean Duration of Locomotion .......

B-3 Analysis of Variance summary Table for Mean Duration of Contact Play .....

B-4 Analysis of Variance Summary Table for Mean Duration of Mixed Play ......:

B-5 Analysis of Variance Summary Table for Mean Duration of Sex Play . . . . . .

B-6 Analysis of Variance Summary Table for Mean Duration of Affiliation . . . . .

B-7 Analysis of Variance summary Table for Mean Duration of object Manipulation . . 


\section{LIST OF ILLUSTRATIONS}

Figure

Page

1. Mean Duration per Observation Session of Non-Social Behaviors Scored .....

$1]$

2. Mean Duration per Observation Session of Social Behaviors Scored......。

3. Mean Duration per Observation Session of the Time spent by Infants on their Mothers, off their Mothers at the same Ievel of the Cage and off their Mothers at other Levels of the Cage...... 


\section{ABSTRACT}

Two female and three male infant squirrel monkeys (Saimiri sciureus) were separated from their mothers at a mean age of 169 days. All had been reared from birth in a large communal cage. The experiment consisted of three five-day periods: (1) preseparation baseline, (2) separation, and (3) reunion. Throughout the expeximent, each infant was observed for ten minutes per day. Frequency and duration measures were recorded for activity play, locomotion, object manipulation and disturbance. Social behaviors recorded were contact play, mixed play, competition play, sex play, affiliation, display and aggression.

The most noticeable change during separation was in the depression of activity play, contact play, mixed play, object manipulation and sex play. Affiliative behaviors, viz., approach and huddling, increased during separation, as did locomotion.

After reunion, locomotion and affiliation returned to baseline levels, while contact play, mixed play, and object manipulation remained depressed. When compared to preseparation levels, the time spent by the infants on their mothers increased, while the time spent off their mothers and at other levels of the cage decreased. 


\section{INTRODUCTION}

Systematic investigations of the effects of motherinfant separation in non-human primates began only ten years ago. All of the experiments conducted so far, except one (Kaplan, 1970), have employed old world monkeys, specificalIy, rhesus, pigtail and bonnet macaques (Macaca mulatta, M. nemestrina, and … radiata, respectively); Kaplan used squirrel monkeys, (Saimiri sciureus).

Despite the variety of separation techniques used, there is considerable consistency in the results of the separation experiments with rhesus monkeys. Studies performed by Seay, Hansen and Harlow (1962), Seay and Harlow (1965), Spencer-Booth and Hinde (1967, 1971a, 1971b), and Hinde and Spencer-Booth (1971) have revealed a cluster of behavioral changes shown by rhesus monkey infants following separation from, and subsequent reunion with, their mothers. During periods of separation from their mothers, infant rhesus monkeys increased distress calling and crying and decreased locomotion and social play. Reunion with their mothers produced initial increases in close contact with their mothers compared to preseparation baseline levels. Recovery of social play and locomotion usually followed within a few days after reunion. 
Comparative studies of maternal separation effects on group living pigtail and bonnet monkey infants (Kaufman and Rosenblum, 1967, 1969) revealed marked interspecies differences. When their mothers were removed from the group, pigtail monkey infants demonstrated depression of play and locomotor activity, similar to rhesus monkeys, while bonnet monkey infants' behavior remained unchanged.

In Kaplan's (1970) experiment, individually housed squirrel monkey mother-infant dyads were separated for seven days and then re-united. During separation, the infants vocalized more than they had before separation, but their locomotion levels remained unchanged. Following reunion with their mothers, the infants' vocalizations returned to preseparation levels and locomotion decreased as a result of the infants spending more time on their mothers than they had before separation.

The experiments discussed above strongly suggest that the effects of maternal separation on infants' behavior differ substantially across primate species. As Rosenblum and Kaufman (1968) have indicated, separation studies are valuable in comparing the relative influences of mother and group upon the social development of young primates. Infant pigtail monkeys receive early social influence almost exclusively from their mothers, whereas bonnet monkey infants receive a large amount of early social experience from other 
adult and juvenile members of their primary group (the group in which they are reared).

The present experiment was designed to investigate maternal separation in squirrel monkeys raised in a group. Kaplan's (1970) subjects were squirrel monkeys whose early social experiences came solely from their mothers. Further, his separation procedure involved social isolation in addition to maternal separation; the infants were housed singly during separation. 
METHOD

\section{Subjects}

The subjects for this experiment were three male and two female squirrel monkey infants (Saimiri sciureus) reared from birth with their mothers, in a communal cage within the laboratory. The subjects were not handled or otherwise disturbed until separation from their mothers. The mean age of the subjects at separation was 169 days (range $=153-186$ days).

\section{Apparatus}

The cage in which the experiment was conducted and in which the subjects were reared from birth measured two meters on each edge. Three shelves attached step-wise to the back of the cage, two perches and one swing furnished the cage. The room in which the cage was located was separated from the main laboratory squirrel monkey colony. Plastic toys (e.g.., small airplanes, balls and blocks) were provided for the subjects.

The data recording apparatus consisted of key operated frequency and duration counters and four foot-operated electric timers. These devices were located on an elevated platform placed three feet in front of the cage. 


\section{Procedure}

Care and Maintenance of the subjects

The subjects and their mothers were fed twice daily, once at 0700 by the laboratory staff, and again at 1600 by the experimenter. Ambient temperature was maintained at approximately $31^{\circ} \mathrm{C}$, and relative humidity at 55-60\%. The normal 12 hour light-dark cycle, from 0700-1900 was maintained throughout the experiment.

Experimental Treatment

Preseparation. In order to establish baseline levels for the behaviors measured, data were collected for five days prior to the mothers' removal from the cage. During this period, the only change in the subjects' daily routine was the experimenter's presence for data collection.

Separation. On the day of separation, the subjects' mothers were fed sugar cubes containing $4 \mathrm{mg}$. of Sernylan (Phencyclidine hydrochloride), an immobilizer, in order to reduce the effects of the separation procedure to the mothers, infants and experimenter. This endeavor was only partially successful since only two of the five mothers ingested enough of the arugged sugar cube to produce the desired reduced responsiveness. Separation of the other three mothers from their infants resulted in more resistance than obtained from the other two. Separation was performed at loo $\mathrm{hr}$. on the sixth day of the experiment, and was carried out by removing 
all mothers from the group cage simultaneously and placing them in another group cage in a separate room. Data were collected on the day of separation in the same manner as during preseparation. The infants were separated from their mothers for five days.

Reunion. At $1000 \mathrm{hr}$. on the day of reunion (day eleven of the experiment), all mothers were simultaneously replaced in the group cage containing their infants. Observations on this day and on the remaining days were conducted as they had been previously.

Behavioral Observations. Observation periods always began promptly at $1500 \mathrm{hr}$. and lasted for 50 minutes. Each subject was observed on each day of the experiment during a ten-minute scoring period. The order of testing for each subject was randomized across days.

Absolute frequencies and durations of infant nonsocial and infant-infant social behaviors were recorded during all phases of the experiment.

Infant non-social behaviors measured, together with their defining criteria were:

$$
\begin{aligned}
\text { Activity play - } & \text { vigorous locomotion, swinging } \\
& \text { or jumping, either singly or } \\
& \text { in combination. } \\
\text { Locomotion } & \text { movement of a distance greater } \\
& \text { than one body length. } \\
\text { object direct - } & \text { visual (within approximately three } \\
& \text { inches) or tactual exploration, or } \\
& \text { play directed toward any part of } \\
& \text { the cage or objects placed within. }
\end{aligned}
$$


Infant-infant social behaviors measured were:

\begin{tabular}{|c|c|}
\hline Contact play & $\begin{array}{l}\text { - initiation or reception of } \\
\text { wrestling and/or play fighting. }\end{array}$ \\
\hline Mixed play & $\begin{array}{l}\text { - initiation or reception of play } \\
\text { involving predominately chasing. }\end{array}$ \\
\hline Competition & $\begin{array}{l}\text { - initiation or reception of an } \\
\text { attempt to take away toys or } \\
\text { other objects from or by another } \\
\text { infant. }\end{array}$ \\
\hline sex play & $\begin{array}{l}\text { - Initiation or reception of mount- } \\
\text { ing, with or without thrusting. }\end{array}$ \\
\hline Affiliation & $\begin{array}{l}\text { - initiation or reception of ap- } \\
\text { proach or hudding. }\end{array}$ \\
\hline Display & $\begin{array}{l}\text { - initiation (at any distance from } \\
\text { another infant), or reception } \\
\text { (from within 15 cm.), of hind } \\
\text { limb abduction, with or without } \\
\text { vocalization. }\end{array}$ \\
\hline Aggression & $\begin{array}{l}\text { - subject bites or is bitten by } \\
\text { another infant so as to elicit } \\
\text { avoidance, distress vocalization } \\
\text { or retaliatory action. }\end{array}$ \\
\hline Disturbance & $\begin{array}{l}\text { - crying or shrieking for any rea- } \\
\text { son, observed or not. }\end{array}$ \\
\hline
\end{tabular}

During preseparation and reunion, separate durations were recorded for the time spent by the infants on their mothers, off their mothers and at the same level of the cage, and off their mothers and at another level of the cage. Level was defined as vertical separation greater than 30 centimeters. 
Statistical Analysis of Results

Unweighted means analyses of variance (Winer, 1971)

were used to analyze mean durations of infant non-social and infant-infant social behaviors as a function of sex and separation. Subsequent comparisons of the mean scores obtained from the three experimental periods were made using Scheffé's (1953) multiple comparisons method. As suggested by Scheffé, differences between means were considered reliable if ${ }^{\infty}<.10$. In addition to comparisons among the preseparation, separation and reunion periods as a whole, comparisons were made between the last day of separation and the last day of reunion. These comparisons were made for those behaviors which showed reliable changes between any two experimental periods to discover whether there were any trends toward recovery across days in any of the experimental periods. Since the distributions of last days' differences deviated from normal, the Wilcoxon Signed Ranks Test (Wilcoxon and Wilcox, 1964) was used:for the analyses of differences between mean scores for the last days' comparisons. With $\mathrm{n}=5$ differences between paired observations, one odd-signed difference has a probability of occurrence of less than .05 (one-tailed), provided that the odd-signed difference has the lowest absolute value of all differences. Comparisons between preseparation and reunion in the mean amount of time spent by the infants on their mothers, off off their mothers at the same level of the cage, and off 
their mothers at other levels of the cage were also made using the Wilcoxon Signed Ranks. Test. 
RESULTS

Figure 1 illustrates changes in the nonsocial behaviors scored during separation and after reunion. During the separation period, activity play decreased $(p<.10)$. After reunion, the figure indicates a nonsignificant increase, compared to separation. Object manipulation also decreased during separation $(p<: 10)$ and remained depressed after maternal reunion $(p<.10)$. Locomotion increased during separation $(p<.01)$, and after reunion returned to baseline levels $(\mathrm{p}<.01)$. Analysis of variance summary tables for non-social, infant-infant social behaviors are presented in Appendix B.

Changes in social behaviors during separation and after reunion are illustrated by Figure 2. During separation, reliable decreases were observed in contact play $(p<.01)$, mixed play $(p<.05)$ and sex play $(p<.10)$. After maternal reunion, contact play and mixed play increased from the levels observed during separation $(p<.01, p<.10$, respectively), but were still depressed when compared to preseparation levels $(p<.01, p<.05$, respectively). Contact play also showed a reliable interaction between sex and separation $(p<.025)$. Females showed more contact play than males during preseparation $(p<.05)$ but no post separation 

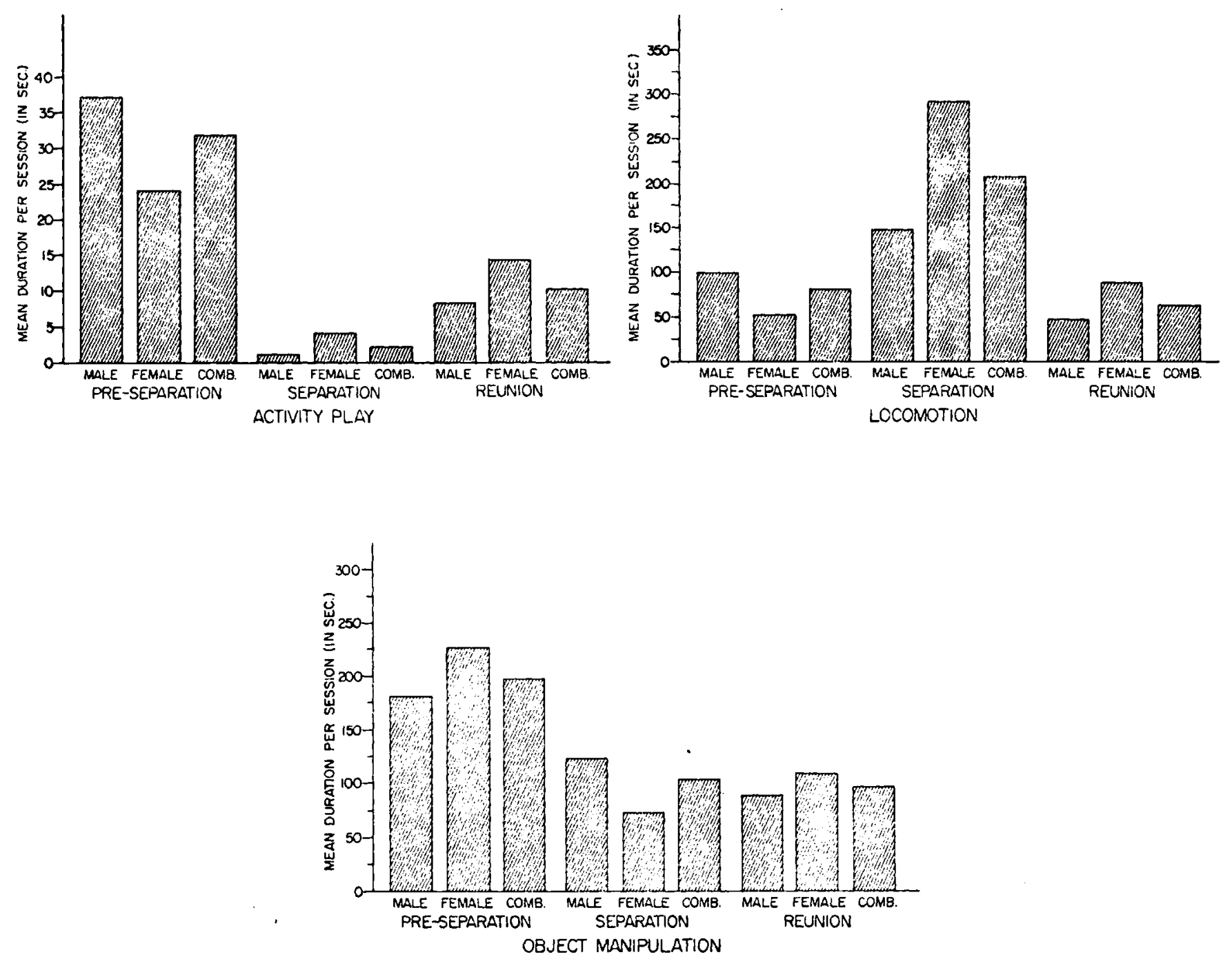

Figure 1. Mean Duration per Observation Session of Non-Social Behaviors scored. 

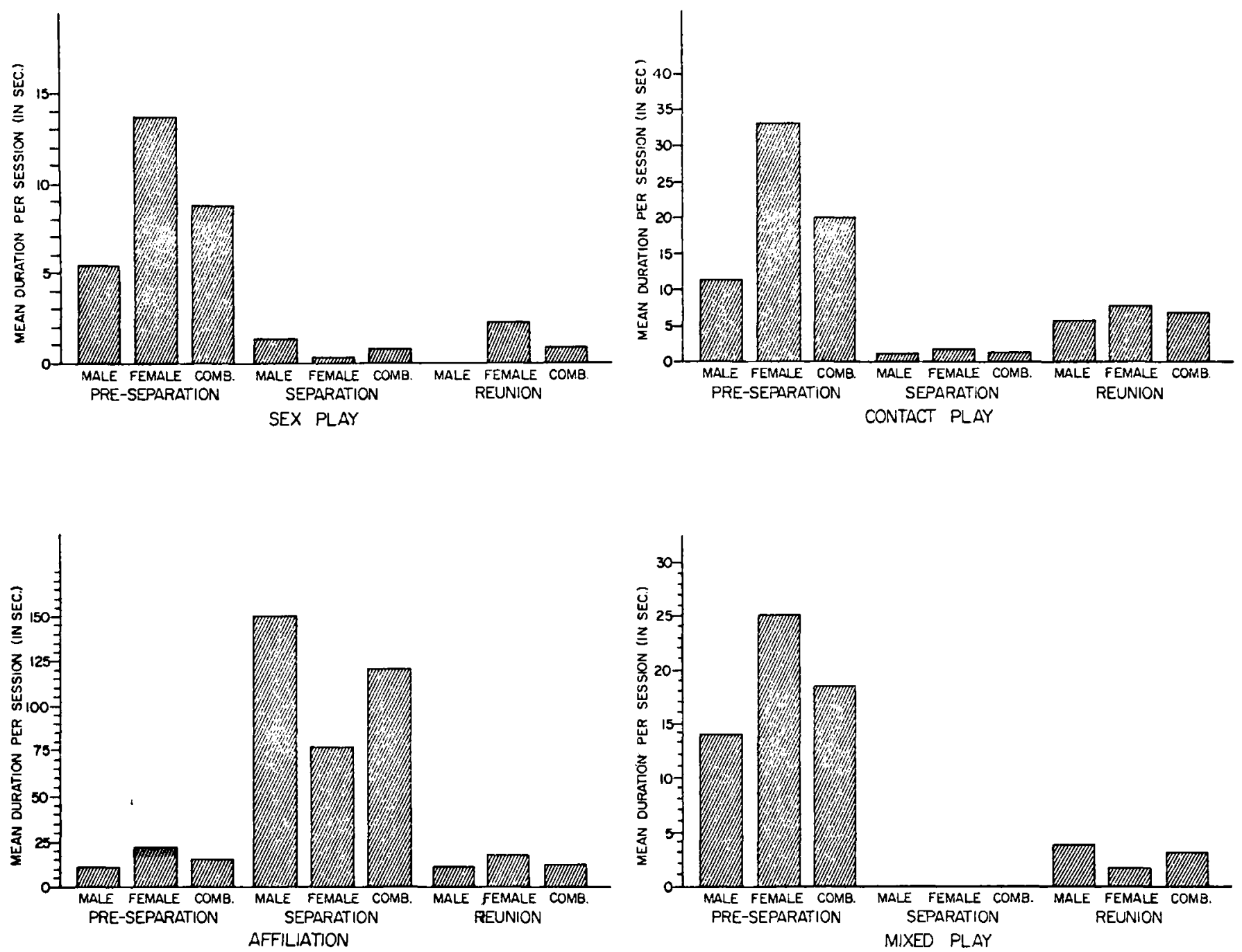

Figure 2. Mean Duration per Observation Session of Social Behaviors scored. 
or post reunion differences. Infant-infant affiliative behaviors, viz., approach and huddling, increased during separation $(p<.05)$, and then returned to preseparation baseline levels after reunion $(\mathrm{p}<.05)$. Competition play, display, aggression and disturbance (crying, shrieking) did not change reliably during the experimental periods (see Appendix A, Table 1, for a table of mean scores and subsequent comparisons). A comparison between the last day of preseparation and the first day of separation for duration of crying revealed a reliable increase $(p<.05)$. A comparison between the first day of separation and the last day of separation for duration of crying showed a reliable decrease $(p<.05)$, indicating recovery of this behavior during separation (Appendix A, Table 2)。

Comparisons between the last day of preseparation and the last day of separation, and between the last day of separation and the last day of reunion were made in order to ascertain whether there were any trends toward recovery in either separation or reunion periods. These last day comparisons were made for activity play, sex play, locomotion, contact play, mixed play, affiliation and object manipulation. The only behavior which showed a reliable trend toward recovery after reunion, was contact play $(p<.05)$ (Appendix A, Table 3).

The difference in the infants' behavior toward their mothers immediately after reunion, compared to the last day 
of preseparation was striking. Figure 3 illustrates comparisons of mean durations per observation session of the location of the infants relative to their mothers during preseparation and reunion. The increase in time spent on the mothers $(p<.05)$ and the concomitant decreases in time spent off the mothers at the same level (n.s.) and other levels of the cage $(p<.05)$ is largely accounted for by the infants' behavior on the day of reunion and on the day after reunion. On these two days, all infants spent at least half of the observation session on their mothers. On the last day of preseparation, none of the infants was seen on its mother. During the last three observation sessions after reunion, all of the infants began to spend more time off their mothers, and during the fifth observation session after reunion, none of the infants was observed on its mother. 


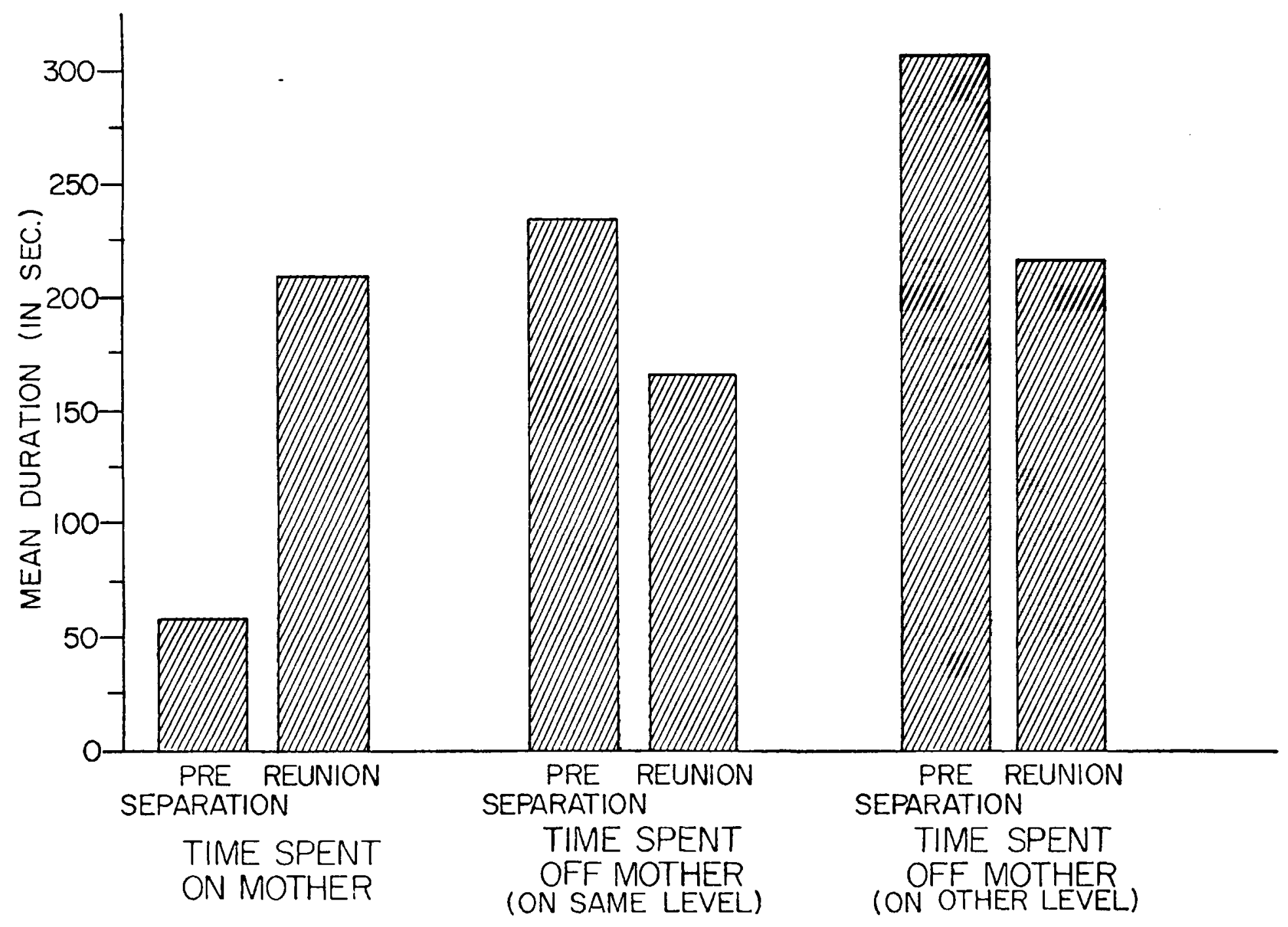

Figure 3. Mean Duration per Observation Session of the Time spent by Infants on their Mothers, off their Nothers at the same Level of the Cage and off 


\section{DISCUSSION}

For the infants in this experiment, the removal of mother had pronounced effects, most of which persisted through the period of separation and even after reunion with their mothers. The virtual disappearance of active social behaviors, contact play, sex play, and mixed play after separation is consistent with results obtained in the infant rhesus and pigtail monkey studies cited above. However, the depression characteristic of rhesus and pigtail infants during periods of maternal separation was not observed in this experiment. A consistent result during separation for all of the present subjects was the increase in locomotion, stereotyped pacing, combined with crying for the first two days after separation, which persisted throughout the separation period. This latter result, combined with the observed increased social huddling is not consistent with the pattern of depression observed in rhesus and pigtail macaques.

As Rosenblum and Kaufman (1968) have indicated, sepatation studies provide an informative way of distinguishing maternal influence from that provided by the group with which the infant is reared upon the social development of the infant. Young bonnet monkeys separated from their mothers, but not from their primary group, show virtually no 
disturbance following an initial short period of agitation. Bonnet monkey mothers do not interfere with their infants' ventures, nor with approaches to their infants by other members of the group as do pigtail monkey mothers (Rosenblum and Kaufman, 1967). Thus for bonnet monkey infants, group companions provide much of their early social experience and are as functional in providing cues for organized social and nonsocial behavior as is the mother for pigtail monkey infants. Further, attachment to primary groups has been shown to be as specific as attachment to a specific mother. Kaufman and Rosenblum (1969) reported that an infant bonnet monkey separated from its mother and placed in a strange group was attacked as severely as an infant pigtail monkey given the same treatment.

Spencer-Booth and Hinde (1971a) reported that during separation, some but not all of their infant rhesus monkeys sought out group companions. They noted that these subjects showed more locomotion and less distress calling during separation than those subjects which did not go to group companions. However, they indicated that the antecedent condition for seeking companionship from other members of the group appeared to be the higher activity levels demonstrated by these subjects during preseparation rather than interactions with group members prior to maternal separation.

A frequently cited theoretical base for separation studies is that of Bowlby (1961)。According to Bowlby. 
separation of an infant from its mother activates three stages of organized and innate patterns of behavior, protest, despair and detachment. Protest is defined as an increase in crying and activity immediately following separation, despair follows protest and is defined as lethargy and general depression. Detachment occurs when the infant has finally accepted the permanence of the loss of its mother and is manifested in the delay and/or resistance with which some human infants re-establish maternal contact. In the present experiment, as in several other non-human primate separation experiments, no detachment occurred; the infants went to their mothers immediately upon reunion. In experiments with rhesus and pigtail monkey infants, both protest and despair patterns occurred, whereas, in studies with bonnet monkey infants and squirrel monkey infants, including the present one, despair patterns did not occur. It appears that the major difficulty in testing Bowlby's theory with non-human private experiments is the focusing upon the mother as the object of primary attachment. To be sure, in many species, the mother does indeed provide most of the social input for infants. However, at least in bonnet monkeys (Rosenblum and Kaufman, 1967) and squirrel monkeys (Rosenblum, 1968; Du Mond, 1968), neonates attract a good deal of attention from other members of the group, and much of this attention is not prevented by the mother as it is in pigtail monkeys (Rosenblum and Kaufman, 
1967). Aunt-infant behaviors in squirrel monkeys have often been observed in this laboratory. Further, squirrel monkey and bonnet monkey mothers are not as restrictive in allowing their infants to move about in the group as are pigtail monkey mothers (Rosenblum, 1968).

An alternate theoretical base for separation experiments is the theory proposed by Cairns (1966). Cairns' proposed that ". mammalian attachment behavior is determined by: (a) the length of association with an object in a given context, and (b) the relative cue weight of the object." When the salient cue or any subset thereof is removed from the infant, a significant aisruption of ongoing behavior is predicted. The amount and duration of the disruption is presumed to be a function of the stimulus weight of the cue (or subset), and the number of response systems that have been conditioned to it. The advantage of Cairns' theory is that it takes into account the entire milieu in which the organism is reared, and thus makes it possible, through separation studies; to assess the relative salience to the infant of each part of the environment.

In conclusion, it follows from the argument above, that pigtail and perhaps rhesus monkey mothers constitute a more salient cluster of cues to their infants since maternal separation brings about severe behavioral disruption in these species. Bonnet monkey primary groups provide most of 
the salient cues to infants of that species and for squirrel monkeys it appears that a similar rearing condition is involved. 
APPENDIX A

TABLES OF MEAN DURATIONS FOR COMBINED DAYS AND SELECTED DAYS 
TABIE A-I

MEAN DURATION (IN SECONDS) PER OBSERVATION SESSION OF SCORED BEHAVIORS

\begin{tabular}{|c|c|c|c|c|c|c|c|c|c|c|c|c|c|}
\hline \multirow{2}{*}{ 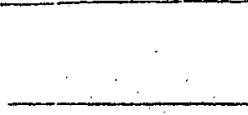 } & \multicolumn{3}{|c|}{ Pre-separation } & \multicolumn{3}{|c|}{ Separation } & \multicolumn{3}{|c|}{ Reunion } & \multicolumn{4}{|c|}{$\begin{array}{c}\text { Post-Hoc Comparisons, } \\
\text { combined Means }\end{array}$} \\
\hline & M & $\mathrm{F}$ & comb. & M & $\mathrm{F}$ & Comb. & $M$ & $\mathrm{E}$ & Comb. & $\mathrm{P}-\mathrm{s}$ & & $S-R$ & $P-R$ \\
\hline Activity & & & & & & & & & & & & & \\
\hline Play & 37.33 & 23.75 & 31.90 & 1.00 & 3.50 & 2.00 & 8.07 & 14.05 & 10.46 & .10 & $\downarrow$ & N.S. & N.S. \\
\hline Eocomotion & 99.00 & 52.20 & 80.30 & 148.80 & 292.92 & 206.46 & 47.50 & 84.90 & 62.48 & .01 & $\uparrow$ & .01 & N.S. \\
\hline Contact & & & & & & & & & & & & & \\
\hline Play & 11.27 & 33.30 & 20.08 & 0.94 & 1.20 & ]. .04 & 5.90 & 7.70 & 6.62 & .01 & $\downarrow$ & .01 & .01 \\
\hline Mixed & & & & & & & & & & & & & \\
\hline Play & 13.77 & 25.05 & 18.28 & 0.0 & 0.0 & 0.0 & 3.80 & 1.60 & 2.92 & .05 & $\downarrow$ & .10 & .05 \\
\hline Competitive & & & & & & & & & & & & & \\
\hline Play & 11.67 & 20.04 & 15.16 & 21.20 & 7.20 & 15.60 & 7.90 & 10.20 & 8.82 & N.S. & & N.S. & N.S. \\
\hline Sex & & . & & . & & & & & & & & & \\
\hline Play & 5.34 & 13.80 & 8.72 & 1.30 & 0.30 & 0.82 & 0.0 & 2.30 & 0.92 & .10 & $\downarrow$ & N.S. & N.S. \\
\hline Affiliate. & 11.14 & 21.60 & 15.32 & 150.87 & 76.1 & 120.96 & .11 .80 & 16.75 & $13.78^{\circ}$ & .05 & $\uparrow$ & .05 & N.S. \\
\hline Display & 1.53 & 0.0 & 0.92 & 0.30 & 0.0 & 0.18 & 2.43 & 2.25 & 2.36 & N.S. & & N.S. & N.S. \\
\hline Agrression & 0.33 & 2.40 & 1.16 & 4.10 & 3.95 & 3.96 & 0.90 & 0.35 & 0.50 & N.S. & & .10 & N.S. \\
\hline Disturbance & 3.57 & 0.0 & 2.14 & 14.07 & 53.00 & 29.64 & 1.60 & 3.40 & 2.32 & N.S. & & N.S. & N.S. \\
\hline $\begin{array}{l}\text { object } \\
\text { Manipulation }\end{array}$ & 178.50 & 224.85 & 197.04 & 123.79 & 72.9 & 103.43 & 88.40 & 107.30 & 95.98 & .10 & $\downarrow$ & N.S. & .10 \\
\hline
\end{tabular}


TABLE $A-2$

MEAN DURATION OF CRYING IN SECONDS FOR EACH SUBJECT FOR SELECTED DAYS OF THE EXPERIMENT

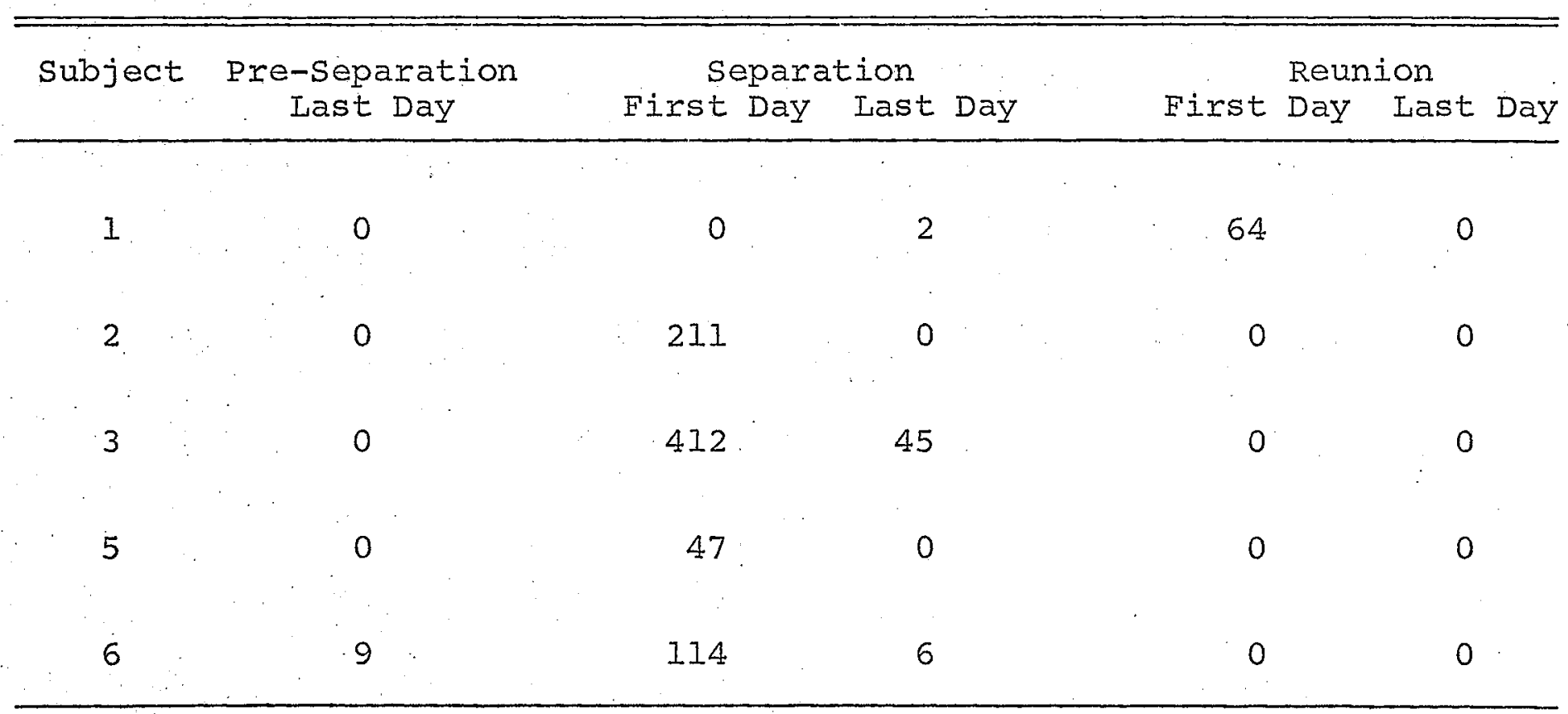


TABLE $A-3$

MEAN DURATION OF SELECTED BEHAVIORS ON THE LAST DAY OF PRESEPARATION, SEPARATION AND REUNION

\begin{tabular}{|c|c|c|c|c|c|c|c|c|c|c|c|c|c|c|c|c|c|c|c|c|c|}
\hline \multirow[t]{2}{*}{ Subject } & \multicolumn{3}{|c|}{$\begin{array}{c}\text { Activity } \\
\text { Play }\end{array}$} & \multicolumn{3}{|c|}{ Locomotion } & \multicolumn{3}{|c|}{$\begin{array}{c}\text { Contact } \\
\text { Play }\end{array}$} & \multicolumn{3}{|c|}{$\begin{array}{l}\text { Mixed } \\
\text { Play }\end{array}$} & \multicolumn{3}{|c|}{$\begin{array}{r}\text { Sex } \\
\text { PIay }\end{array}$} & \multicolumn{3}{|c|}{ Affiliation } & \multicolumn{3}{|c|}{$\begin{array}{c}\text { Object } \\
\text { Manipulation }\end{array}$} \\
\hline & $\mathrm{P}$ & $\mathrm{s}$ & $\mathrm{R}$ & P. & $\mathrm{s}$ & $\mathrm{R}$ & $\mathrm{P}$ & $\mathrm{s}$ & $\mathrm{R}$ & $\mathrm{P}$ & $\mathrm{s}^{2}$ & $\mathrm{R}$ & $\mathrm{P}$ & $\overrightarrow{\mathrm{S}}$ & $\mathrm{R}$ & $\mathrm{P}$ & $s$ & $\mathrm{R}$ & $\mathrm{p}$ & $s$ & $\mathrm{R}$ \\
\hline 1 & 22 & 0 & 19 & 90 & 1028 & 250 & 190 & 0 & 39 & 159 & 0 & 3 & 0 & 0 & 0 & 13 & 37 & 9 & 419 & 85 & 297 \\
\hline 2 & 196 & 0 & 0 & 174 & 16 & $130^{\circ}$ & 6 & 0 & 0 & 8 & 0 & 0 & 9 & 0 & 0 & 9 & 70 & 4 & 587 & 0 & 243 \\
\hline$=3 \ldots$ & 47 & 52 & 25 & 180 & 1066 & 199 & 118 & 0 & 16 & 105 & 0 & 0 & 3 & 0 & 0 & 56 & 8 & 27 & 367 & 12 & 80 \\
\hline 5 & 8 & 0 & 8 & 118 & 111 & 138 & 33 & 0 & 8 & 0 & 0 & 4 & 40 & 15 & 0 & .89 & 78 & 37 & 498 & 663 & 238 \\
\hline 0 & 175 & 2 & 10 & 359 & 206 & 155 & 121 & 2 & 32 & 84 & 0 & $30^{\circ}$ & 32 & 0 & 0 & 16 & 366 & 15 & 155 & 174 & 468 \\
\hline
\end{tabular}


APPENDIX B

ANAIYSIS OF VARIANCE SUMMARY TABLES FOR THE BEHAVIORS SCORED 


$$
\text { TABLE } B-I
$$

ANALYSIS OF VARIANCE SUMMARY TABLE

FOR MEAN DURATION OF ACTIVITY PLAY

\begin{tabular}{|c|c|c|c|c|c|}
\hline Source & $d f$ & SS & MS & $F$ & $\mathrm{P}$ \\
\hline Between & 4 & & & & \\
\hline Sex & 1 & 10.42 & 10.42 & $<1$ & \\
\hline Error & 3 & 729.73 & 243.25 & & \\
\hline Within & 10 . & & & & \\
\hline Treatment & 2 & 2011.85 & 1005.92 & 4.0 & $<.1$ \\
\hline \multicolumn{6}{|l|}{$\begin{array}{c}\text { Treatment } \\
\mathrm{X}\end{array}$} \\
\hline Sex & 2 & 108.88 & 54.44 & $<1$ & \\
\hline Error & 6 & $\quad 1511.95$ & 252.0 & & \\
\hline Total & 14 & & & & \\
\hline
\end{tabular}




\section{TABLE $B-2$}

ANALYSIS OF VARIANCE SUMMARY TABIE FOR MEAN DURATION OF LOCOMOTION

\begin{tabular}{|c|c|c|c|c|c|c|c|}
\hline Source & df & & SS & MS & $F$ & & $\mathrm{P}$ \\
\hline Between & 4 & & & & & & \\
\hline Sex & 1 & & 7257.64 & 7257.64 & 3.65 & $\kappa$ & .2 \\
\hline Error & 3 & & 5967.15 & 1789.06 & & & \\
\hline Within & 10 & & & & & & \\
\hline Treatment & 2 & 1 & 72164.08 & 36082.04 & 34.13 & $<$ & .001 \\
\hline $\begin{array}{c}\text { Treatment } \\
\mathrm{X} \\
\text { Sex }\end{array}$ & 2 & & 21966.92 & 10983.46 & 10.39 & $<$ & .025 \\
\hline Error & 6 & & 6344.34 & 1057.39 & . & & \\
\hline Tota1 & 14 & & & & & & \\
\hline
\end{tabular}




\section{TABLE B-3}

ANAIYSIS OF VARIANCE SUMMARY TABLE

FOR MEAN DURATION OF CONTACT PLAY

\begin{tabular}{|c|c|c|c|c|c|}
\hline Source & $d f$ & SS & MS & $F$ & $\mathrm{P}$ \\
\hline Between & 4 & & & . & \\
\hline Sex & 1 & 232.13 & 232.13 & 5.92 & $<.1$ \\
\hline Error & 3 & 117.63 & 39.21 & & \\
\hline Within & 10 & & & & \\
\hline Treatment & 2 & 1156.32 & 578.16 & 31.74 & $<.001$ \\
\hline $\begin{array}{c}\text { Treatment } \\
\text { X } \\
\text { Sex }\end{array}$ & 2 & 354.24 & 177.12 & 9.73 & $<.025$ \\
\hline & & & & & \\
\hline Error & 6 & 109.3 & 18.22 & & \\
\hline Total & 14. & & & & \\
\hline
\end{tabular}




\section{TABIE $B-4$}

ANAIYSIS OF VARIANCE SUMMARY TABLE FOR MEAN DURATION OF MIXED PLAY

\begin{tabular}{|c|c|c|c|c|c|}
\hline Source & $d f$ & SS & MS & $F$ & $\mathrm{P}$ \\
\hline Between & 4 & & , & & \\
\hline Sex & 1 & 33.48 & 33.48 & $<1$ & \\
\hline Error & 3 & 489.68 & 163.23 & & \\
\hline Within & 10 & & & & \\
\hline Treatment & 2 & 1057.18 & 528.59 & 6.68 & $<.05$ \\
\hline $\begin{array}{l}\text { Treatment } \\
\mathrm{x} \\
\text { Sex }\end{array}$ & 2 & 131.55 & 65.79 & $<1$ & \\
\hline Error & 6 & 475.02 & 79.17 & 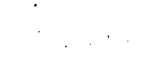 & \\
\hline Total & 14 & & & & \\
\hline
\end{tabular}


TABLE $B-5$

ANALYSIS OF VARIANCE SUMMARY TABLE

FOR MEAN DURATION OF SEX PLAY

\begin{tabular}{|c|c|c|c|c|c|}
\hline source & df & SS & MS & $F$ & $\mathrm{P}$ \\
\hline Between & 4 & & & & \\
\hline Sex & 1 & 55.32 & 55.32 & $N . S$. & \\
\hline Error & 3 & 83.37 & 27.79 & & \\
\hline Within & 10 & & & & \\
\hline Treatment & 2 & $236: 69$ & 118.35 & 5.3 & $<.05$ \\
\hline $\begin{array}{c}\text { Treatment } \\
x \\
\text { Sex }\end{array}$ & 2 & 38.12 & 19.06 & $<1$ & \\
\hline Error & 6 & 134.13 & 22.36 & . & \\
\hline Total & 14 & & & & \\
\hline
\end{tabular}


TABIEE B-6

ANAIYSIS OF VARIANCE SUMMARY TABIE

FOR MEAN DURATION OF AFFIIIATION

\begin{tabular}{|c|c|c|c|c|c|c|}
\hline Source & $d f$ & SS & MS & $E$ & & $\mathrm{P}$ \\
\hline Between & 4 & & & & & \\
\hline Sex & 1 & 1406.67 & 1406.67 & $<1$ & & \\
\hline Error & 3 & 4261.45 & 1420.49 & & & \\
\hline Within & 10 & & & & & \\
\hline Treatment & 2 & 30845.33 & 15422.67 & 5.67 & $<$ & .05 \\
\hline $\begin{array}{c}\text { Treatment } \\
\mathrm{X}\end{array}$ & 2 & 5462.72 & 2731.36 & N.S. & & \\
\hline Sex & & & & & & \\
\hline Error & 6 & 16321.02 & 2720.17 & & & \\
\hline Total & 14 & & & $\cdots$ & & \\
\hline
\end{tabular}




\section{TABLE B-7}

ANALYSIS OF VARIANCE SUMMARY TABLE

FOR MEAN DURATION OF OBJECT MANIPULATION

\begin{tabular}{|c|c|c|c|c|c|}
\hline Source & $d f$ & SS & MS & $\mathrm{F}$ & $\mathrm{P}$ \\
\hline Between & 4 & & & & \\
\hline Sex & 1 & 82.49 & 82.49 & $<1$ & \\
\hline Error & 3 & 19395.07 & 6465.07 & & \\
\hline Within & 10 & & & & \\
\hline Treatment & 2 & 34331.14 & 17165.57 & 4.35 & $<.1$ \\
\hline $\begin{array}{c}\text { Treatment } \\
X \\
\text { Sex }\end{array}$ & 2 & 6031.92 & 3015.96 & 2.04 & $<.2$ \\
\hline Error & 6 & 23693.38 & 3948.9 & & \\
\hline Total & 14 & 1 & & & \\
\hline
\end{tabular}




\section{REFERENCES}

Bowlby, J. (1961). Separation anxiety: A critical review of the literature. Journal of Child Psychology, Psychiatry and Alied Sciences, $1: 251-269$.

Cairns, R. B. (1966).. Attachment behavior of mammals. Psychological Review, 73: 409-426.

Du Mond, Frank V. (1968). The squirrel monkey in a seminatural environment. In $I$. A. Rosenblum and $R$. W. Cooper (Eds.); The Squirrel Monkey. New York: Academic Press. Pp. 87-145.

Hinde, Robert A., and Spencer-Booth, Yvette (1971). Effects of brief separation from mother on rhesus monkeys. Science, 173: 111-118.

Kaplan, Joel. (1970). The effects of separation and reunion on the behavior of mother and infant squirrel monkeys. Developmental Psychobiology. 3: 43-52.

Kaufman, I. C., and Rosenblum, Leonard A. (1967). Depression in infant monkeys separated from their mothers. Science, 155: 1030-1.031.

Kaufman, I.C., and Rosenblum, Leonard A. (1969). Effects of separation from mother on the emotional behavior of infant monkeys. Annals of the New York Academy of Sciences, 159: 681-695.

Rosenblum, Leonard A. (1968). Mother-infant relations and early behavioral development in the squirrel monkey. In I. A. Rosenblum and R.W. Cooper (EdS.), The Squirrel Monkey. New York: Academic Press. Pp. 207-233.

Rosenblum, I. A., and Kaufman, I. C. (1967). Laboratory observations of early mother-infant relations in pigtail and bonnet macaques. In S. Altman (Ed。), Social Communication Among Primates. Chicago: University of Chicago Press. 
Rosenblum, Leonard A., and Kaufman, I. C. (1968). Variations in infant development and maternal loss in monkeys. American Journal of Orthopsychiatry, 38: $418-426$.

Scheffé, H. A. (1953). A method for judging all possible contrasts in the analysis of variance. Biometrika, $40: 87-104$.

Seay, Bill, Hansen, Ernst, and Harlow, Harry F. (1962). Mother-infant separation in monkeys. Journal of Child Psychology, Psychiatry and Allied Sciences, $3: 123-132$.

Seay, Bill, and Harlow, Harry F. (1965). Maternal separation in the rhesus monkey. Journal of Nervous and Mental Disorders, 140: 434-441.

Spencer-Booth, Yvette, and Hinde, Robert A. (1967). The effects of separating rhesus monkey infants from their mothers for six days. Journal of Child Psychology, Psychiatry and Allied Sciences, 7: 179-197.

Spencer-Booth, Yvette, and Hinde, Robert A. (1971a). Effects of six days' separation from mother on 18-32 week-old rhesus monkeys. Animal Behaviour, 19: 174-191.

Spencer-Booth, Yvette, and Hinde, Robert A. (1971b). The effects of 13 days maternal separation on infant rhesus monkeys compared with those of shorter and repeated separations. Animal Behaviour, 19: 595605 .

Wilcoxon, Frank, and Wilcox, Roberta (1964). Some Rapid Approximate Statistical Procedures. Lederle Laboratories, Pearl River, New York.

Winer, B. J. (1971). Statistical principles in Experimental Design, 2nd ed. New York: McGraw-Hill Book Co. 
